\title{
Investigation of Anticorrosion, Antibacterial and In Vitro Biological Performance of Terbium / Gadolinium Dual Substituted Hydroxyapatite Coating on Surgical Grade Stainless Steel for Biomedical Applications
}

\author{
C. SRIDEVI ${ }^{1,3}$, S. SATHISHKUMAR $^{2}$, S. ELAVARASAN $^{2}$ \\ R. RAJAVEL ${ }^{3}$ and P. MAHESWARAN ${ }^{1 *}$
}

${ }^{1}$ Department of Chemistry, PGP College of Arts and Science, Namakkal-637 207, Tamilnadu, India

${ }^{2}$ Synthetic Organic Chemistry Laboratory, Department of Chemistry, Sri Vijay Vidyalaya Colege of Arts and Science, Dharmapuri, Tamilnadu, India.

${ }^{3}$ Department of Chemistry, Periyar University, Salem-636 011, Tamilnadu, India sathish.sskg@gmail.com

Received 17 November 2017 / Accepted 12 December 2017

\begin{abstract}
Development of terbium/gadolinium dual substituted hydroxyapatite on 316L stainless steel (SS) have been studie. The coatings were characterized by Fourier transform infrared spectroscopy (FT-IR), X-ray diffraction (XRD), scanning electron microscopy (SEM) and energy dispersive X-ray analysis (EDAX). The electrochemical results show that the Tb/Gd-HAP coating on 316L SS possesses greatest corrosion resistance in Ringer's solution. The antimicrobial performance was studied for the obtained coatings against the pathogenic bacterial strains $S$. aureus and E. coli. The in vitro cell adhesion test revealed that the Tb/Gd-HAP coating was found appropriate for the formation of new cell growth which proves the enhanced biocompatible nature of the coating. Thus, the Tb/Gd-HAP coating on 316L SS can play a key role in the biomedical applications.
\end{abstract}

Keywords: Tb and Gd-HAP, 316L SS, Antibacterial activity, Corrosion resistance, Bioactivity

\section{Introduction}

Metallic biomaterials such as cobalt alloys, titanium alloys, 316L stainless steel (SS) and magnesium alloys are mostly used as orthopedic implants due to their good strength and toughness ${ }^{1-4}$. However, there is for all time a concern about their corrosion resistance in physiological medium and their good biocompatibility. Austenitic stainless steels are used hugely as human body implants due to availability at low cost, ease of fabrication, excellent 
processability and better mechanical properties ${ }^{5-8}$. The metal surface of austenitic stainless steel is prone to release iron, chromium, nickel ions evidenced in the human body ${ }^{9-11}$. Leached nickel and chromium ions are toxic species and powerful allergens and demonstrated to be carcinogenic. In this regard, decrease in metal ion release is preferred to avoid the harmful effect caused by the corrosion products in the bone formation. In order to overcome the metal ion release, the bioactive and osteointegrated bioceramic coatings especially hydroxyapatite $\left[\mathrm{Ca}_{10}\left(\mathrm{PO}_{4}\right)_{6}(\mathrm{OH})_{2}, \mathrm{HAP}\right]$ was developed on the surface of the implant material ${ }^{12-16}$. Hydroxyapatite widely used as repair materials for bone because of its likeness in chemical composition to the inorganic matrix of the bones and tissues in mammals. The properties of hydroxyapatite were particular to be controlled by its crystal structure and composition. Therefore the substitution of $\mathrm{Ca}^{2+}$ with other metal ions ( $\mathrm{Zn}, \mathrm{Tb}, \mathrm{Sm}, \mathrm{Ce}, \mathrm{Eu}$. etc...) plays an essential role in the improvement of biological performance of hydroxyapatite ${ }^{17-24}$. In particular, Terbium ions plays a major role in improving the biocompatibility and biodegradability of hydroxyapatite bioceramics which enhances the in vitro and in vivo osteoblast cell proliferation and growth. On the other hand, the improved anticorrosion performance of the implant materials should be considered for superior biological activities ${ }^{25}$. Gadolinium is one of the significant trivalent ions in lanthanide series with good anticorrosion behavior ${ }^{26}$. In addition, Gd ions are used as the drug carrier and anticancer agent and the presence of Gd induces the osteoconductivity and cell enlargement. Majeed et al. have previously reported the preparation of $\mathrm{Gd}_{2} \mathrm{O}_{3}$ and Eu: $\mathrm{Gd}_{2} \mathrm{O}_{3}$ nanocrystals and among them $\mathrm{Gd}_{2} \mathrm{O}_{3}$ nanopowders were found to be biologically biocompatible by the cell proliferation test ${ }^{27}$. In present work we achieved the development of Terbium/Gadolinium dual substituted hydroxyapatite on $316 \mathrm{~L}$ SS. The coatings were characterized by Fourier transform infrared spectroscopy (FT-IR), x-ray diffraction (XRD), scanning electron microscopy (SEM) and energy dispersive X-ray analysis (EDAX). The electrochemical results show that the Tb/Gd-HAP coating on the passivated 316L SS possesses greatest corrosion resistance in Ringer's solution. The antimicrobial performance was studied for the obtained coatings against the pathogenic bacterial strains $S$. aureus and E. coli and also the in vitro cell viability test was performed using MC3T3-E1 cell lines to estimate the bioactivity of the coating. Thus, the Tb, Gd-HAP coating on 316L SS will serve as a promising candidate with improved corrosion resistance, antibacterial property and osteocompatibility.

\section{Experimental}

Type 316L SS (procured from Steel Authority of India, Ltd. (SAIL), India), having an elemental composition (wt \%) of $0.0222 \mathrm{C}, 0.551 \mathrm{Si}, 1.67 \mathrm{Mn}, 0.023 \mathrm{P}, 0.0045 \mathrm{~S}, 17.05$ $\mathrm{Cr}, 11.65 \mathrm{Ni}, 2.53 \mathrm{Mo}, 0.136 \mathrm{Co}, 0.231 \mathrm{Cu}, 0.0052 \mathrm{Ti}, 0.0783 \mathrm{~V}, 0.0659 \mathrm{~N}$ and $\mathrm{Fe}$ (balance), was used as the metal substrate for the electrodeposition. The 316L SS substrate with a size of $10 \times 10 \times 3 \mathrm{~mm}$ were embedded in epoxy resin, leaving an area of $1 \mathrm{~cm}^{2}$ for exposure to the electrolyte solution. Prior to electrodeposition, these substrates were abraded with different grades of silicon carbide (SiC) emery papers from 400 grit to 1200 grit. After polishing, these samples were ultrasonically cleaned and thoroughly washed with acetone and deionized water for $10 \mathrm{~min}$ and finally, rinsed in deionized (DI) water and dried. In order to improve the anticorrosion property, the 316L SS surface was passivated using $0.4 \mathrm{M}$ borate buffer solution $(\mathrm{pH} 9.3)$ at $640 \mathrm{mV}$ $v s$. saturated calomel electrode (SCE) for $2 \mathrm{~h}$ in potentiostatic condition using electrochemical workstation (Model CHI 760C, CH Instruments, USA). 


\section{Preparation of electrolyte solution}

The electrolyte solution for Tb,Gd-HAP were prepared by dissolving analytical grade $0.3 \mathrm{M}$ calcium nitrate hexahydrate $\left(\mathrm{Ca}\left(\mathrm{NO}_{3}\right)_{2} \cdot 6 \mathrm{H}_{2} \mathrm{O}\right), 0.1 \mathrm{M}$ Terbium nitrate hexahydrate $\left(\mathrm{Tb}\left(\mathrm{NO}_{3}\right)_{2}, 6 \mathrm{H}_{2} \mathrm{O}\right)$ and $0.1 \mathrm{M}$ Gadolinium nitrate hexahydrate $\left(\mathrm{Gd}\left(\mathrm{NO}_{3}\right)_{2}, 6 \mathrm{H}_{2} \mathrm{O}\right)$ in (DI) deionized water. The $0.3 \mathrm{M}$ diammonium hydrogen phosphate $\left(\left(\mathrm{NH}_{4}\right)_{2} \mathrm{HPO}_{4}\right)$ solution was dissolved in deionized water and the solution was mixed with $(\mathrm{Ca}+\mathrm{Tb}+\mathrm{Gd}) / \mathrm{P}$ molar ratio of 1.67 at room temperature $\left(28 \pm 1{ }^{\circ} \mathrm{C}\right)$. Then the solution was under magnetic stirring for $4 \mathrm{~h}$ and the $\mathrm{pH}$ of the electrolyte was adjusted to 4.7 using ammonia hydroxide solution. All the chemicals were analytic grade reagents (purchased from sigma Aldrich) and used without further purification.

\section{Electrodepostion of $\mathrm{Tb}, \mathrm{Gd}-\mathrm{HAP}$}

The Tb, Gd-HAP coating on 316L SS was carried out in three different constant cathodic potentials of $-1200,-1400$ and $-1600, \mathrm{mV} v s$. SCE for the time of $1 \mathrm{~h}$ in potentiostatic mode by maintaining the temperature at $50{ }^{\circ} \mathrm{C}$. After the electrodeposition the coating substrates were gently rinsed with deionized water, dried in the air and then stored in a noculums $\mathrm{s}$ for additional studies.

\section{Surface characterization}

The $\mathrm{Tb}$, Gd-HAP coating materials were analyzed using Fourier transform infrared spectroscopy (FT-IR) using a Bruker Tensor ${ }^{27}$. The FT-IR spectra were recorded from 4000$400 \mathrm{~cm}^{-1}$ with the region of $4 \mathrm{~cm}^{-1}$ resolution by using the $\mathrm{KBr}$ pellet technique method. The crystanality structure of coated samples was investigated by x-ray diffraction PANalytical $X^{\prime}$ Pert PRO diffractometer in the $2 \theta$ angle between $20^{\circ}-60^{\circ}$ with $\mathrm{Cu} \mathrm{K} \alpha$ radiation $(1.5406$ $\AA$ ). The surface morphology and elemental composition of as a developed duplex layer coating were evaluated by a high resolution scanning electron microscopy (HRSEM, JSM 840A, JEOL-Japan) equipped with EDAX.

\section{Antibacterial activity}

The antibacterial activity of the Tb/Gd-HAP coating at different concentrations have been investigated against two bacterial strains $S$. aureus (ATCC 25923) and E. coli (ATCC 25922) via agar disc diffusion method. The Mullar-Hinton agar plates were prepared by pouring $15 \mathrm{~mL}$ of a molten medium into sterile Petri plates. The plates were allowed to solidify for $\sim 15 \mathrm{~min}$ and $0.1 \%$ of noculums suspension was swabbed uniformly over the agar until the inoculums became invisible. Different concentrations $(25,50,75,100$ and $125 \mu \mathrm{L})$ of Tb,Gd-HAP coating were loaded onto $5 \mathrm{~mm}$ sterile individual discs, followed by incubation of plates at $37{ }^{\circ} \mathrm{C}$ for $24 \mathrm{~h}$. The zone of inhibition was observed by measuring the width of the inhibited zone.

\section{Osteocompatibility studies}

The cell proliferation of MC3T3-E1 cells on Tb/Gd-HAP was studied using MTT assay on day 1, 3 and 5. To determine the cytotoxicity of the samples at different conditions, MC3T3-E1 cells were seeded in 12-well plates at 104 cells $/ \mathrm{mL}$ in a humidified $5 \% \mathrm{CO}_{2}$ atmosphere. Each time, $400 \mu \mathrm{L}$ of MTT reagent $(1 \mathrm{mg} / \mathrm{mL})$ was added to each well and incubated for $4 \mathrm{~h}$ under the same conditions. Finally, MTT reagent was removed and $400 \mu \mathrm{L}$ of dimethyl sulfoxide (DMSO, Sigma-Aldrich) was added for dissolving the formazan crystals and the absorbance was measured at $560 \mathrm{~nm}$ in an ELISA microplate reader and then the cell viability (as a percentage) was calculated, with respect to the control, as follows:

$$
\% \text { Cell viability }=[\mathrm{A}] \text { Test } /[\mathrm{A}] \text { Control } \times 100
$$




\section{Results and Discussion}

\section{FT-IR Analysis}

The FTIR spectrum of Tb/Gd-HAP coating on 316L SS sample is shown in Figure 1. The characterized peaks at $472 \mathrm{~cm}^{-1}, 588 \mathrm{~cm}^{-1}, 602 \mathrm{~cm}^{-1}$ as well as the peaks attributed in $874 \mathrm{~cm}^{-1}$ and $961 \mathrm{~cm}^{-1}$ were assigned in the phosphate group in Tb/Gd-HAP. The sharp peaks at $1091 \mathrm{~cm}^{-1}$ and $1025 \mathrm{~cm}^{-1}$ were due to the asymmetric stretching of P-O bond of phosphate groups. In addition, absorption bands at $3572 \mathrm{~cm}^{-1}$ and $633 \mathrm{~cm}^{-1}$ are due to the stretching and bending vibration of $\mathrm{OH}^{-}$groups of $\mathrm{Tb}, \mathrm{Gd}-\mathrm{HAP}$, respectively. The broad band at $3427 \mathrm{~cm}^{-1}$ and a peak at $1624 \mathrm{~cm}^{-1}$ are assigned for the stretching and bending mode of the $\mathrm{H}_{2} \mathrm{O}$ molecules. Thus, the FTIR spectrum clearly evidenced the formation of $\mathrm{Tb}, \mathrm{Gd}-$ HAP coating on $316 \mathrm{~L} \mathrm{SS}$.

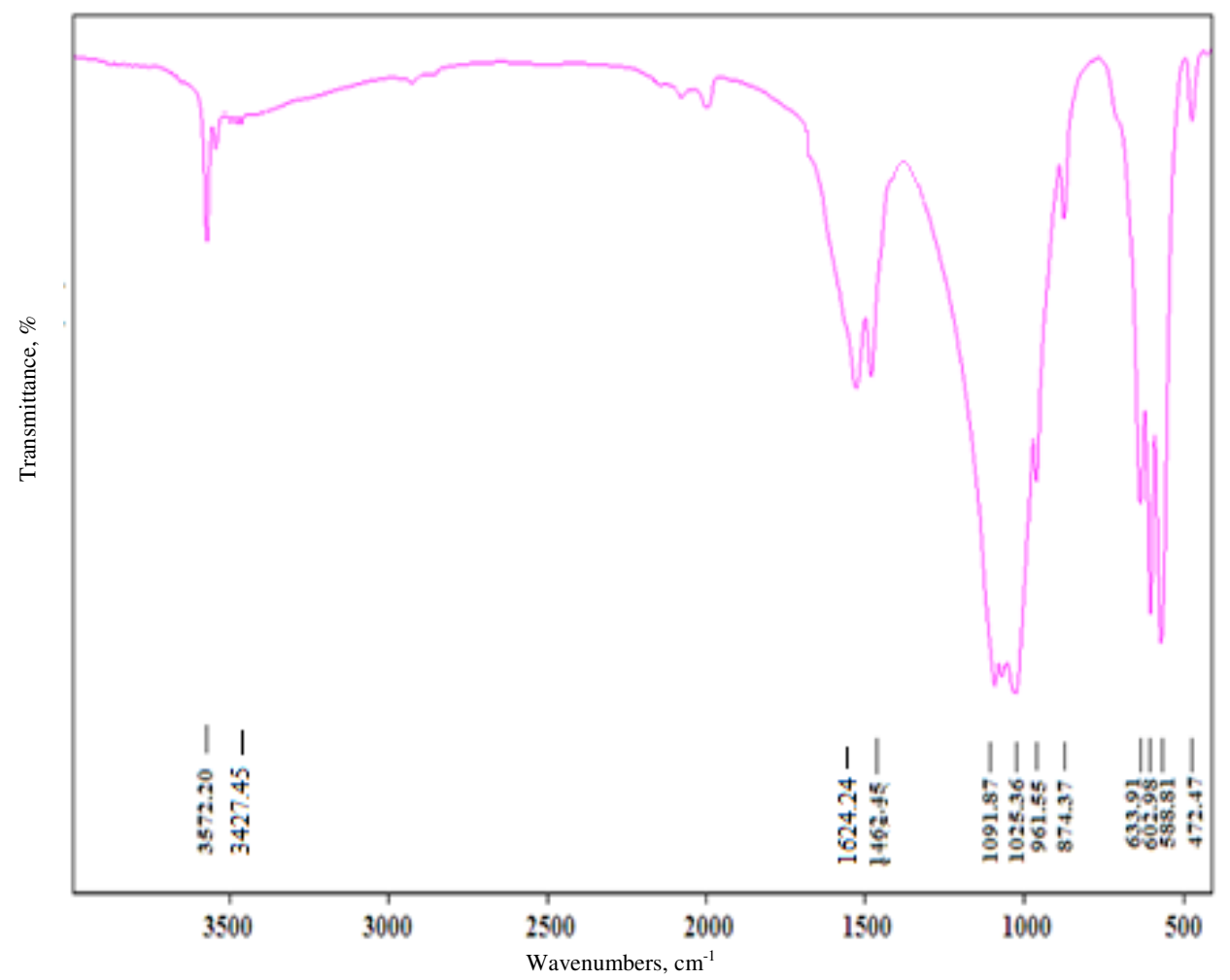

Figure 1. FT-IR spectra of Tb,Gd-HAP coating on 316 L SS

\section{$X$-Ray diffraction studies}

The XRD pattern of as developed Tb,Gd-HAP coating on 316L SS is shown in Figure 2. The strong diffraction peaks detected for Tb,Gd-HAP are in well agreement with the standard data for HAP (ICDD card No. 09-0432). The main diffraction peaks (Figure 2) are indicated at $2 \theta$ values of $25.6^{\circ}, 31.5^{\circ}, 32.2^{\circ}, 32.8^{\circ} 34.6^{\circ}, 39.8^{\circ}, 46.6^{\circ}$ and 53.1 corresponds to $\mathrm{Tb}$, Gd-HAP and no other secondary peaks were detected. Moreover, the intense diffraction peaks resembles the high crystalline nature of the Tb,Gd-HAP coating as evidenced in the Figure 2. 


\section{Morphological investigations}

The surface morphology of Tb,Gd-HAP coatings on 316L SS at variation voltages of $-1200 \mathrm{mV},-1400 \mathrm{mV}$ and $-1600 \mathrm{mV}$ are showed Figure 3(a-c). The morphological feature of non uniform and not surface covered coating at $-1200 \mathrm{mV}$ shown in the Figure $3 \mathrm{a}$. The Tb, Gd-HAP coatings obtained at $-1400 \mathrm{mv}$ (Figure $3 \mathrm{~b}$ ) produces the fully covered rod like morphology of compare then $-1200 \mathrm{mV}$ (Figure 3a) and $-1600 \mathrm{mV}$ (Figure 3c). Hence, Figure $3 \mathrm{~b}(-1400 \mathrm{mV})$ shows fully covered rod like structure and fixed the optimal condition of $\mathrm{Tb}$, Gd-HAP coating on 316L SS. Figure 3d shows the EDAX spectrum of the Tb, Gd-HAP coated on $316 \mathrm{~L} \mathrm{SS}$. This spectrum indicates the presence of $\mathrm{Ca}, \mathrm{Gd}, \mathrm{Tb}, \mathrm{O}$ and $\mathrm{P}$ there by confirms the existence of Tb,Gd-HAP coating on 316L SS.

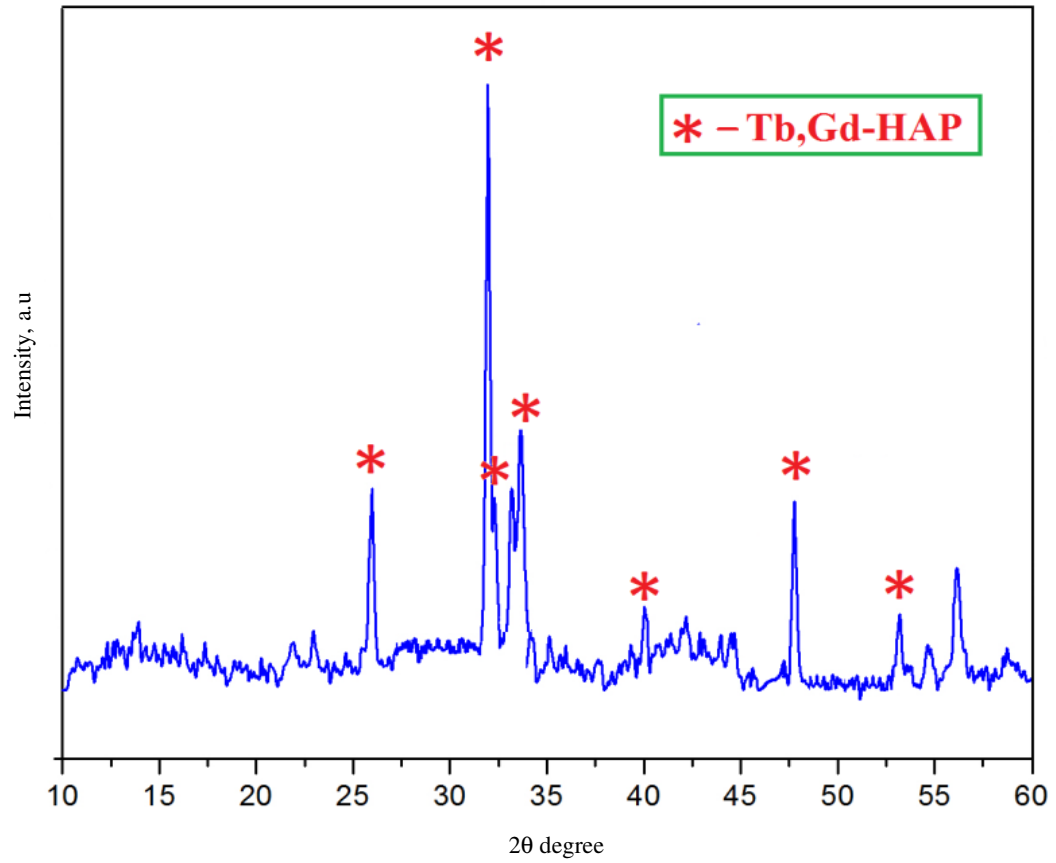

Figure 2. XRD patterns of Tb,Gd-HAP coating on $316 \mathrm{~L}$ SS

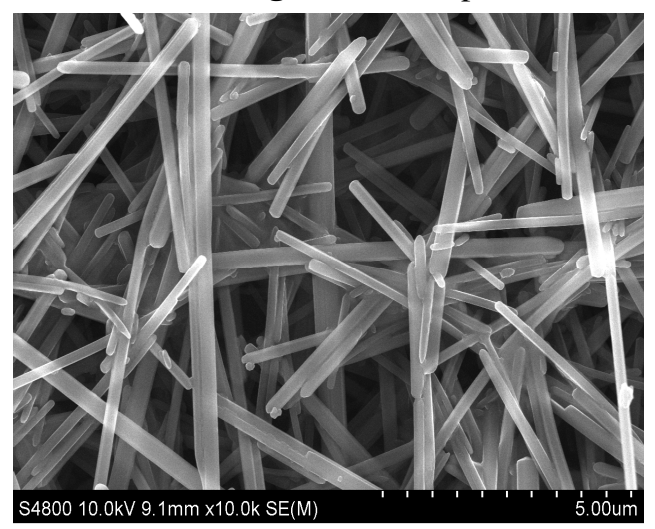

(a)

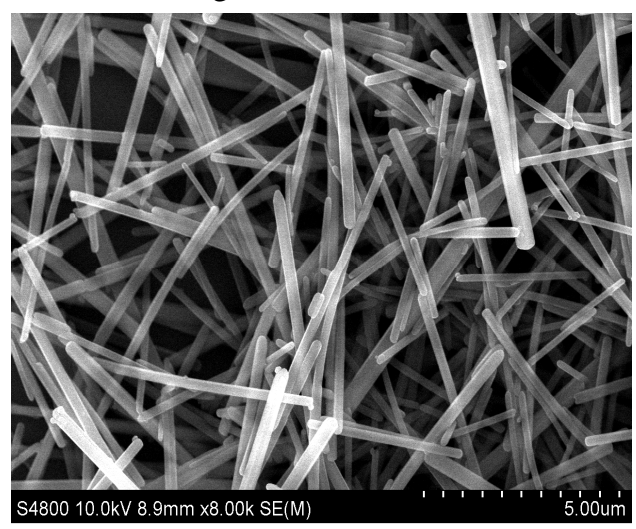

(b) 


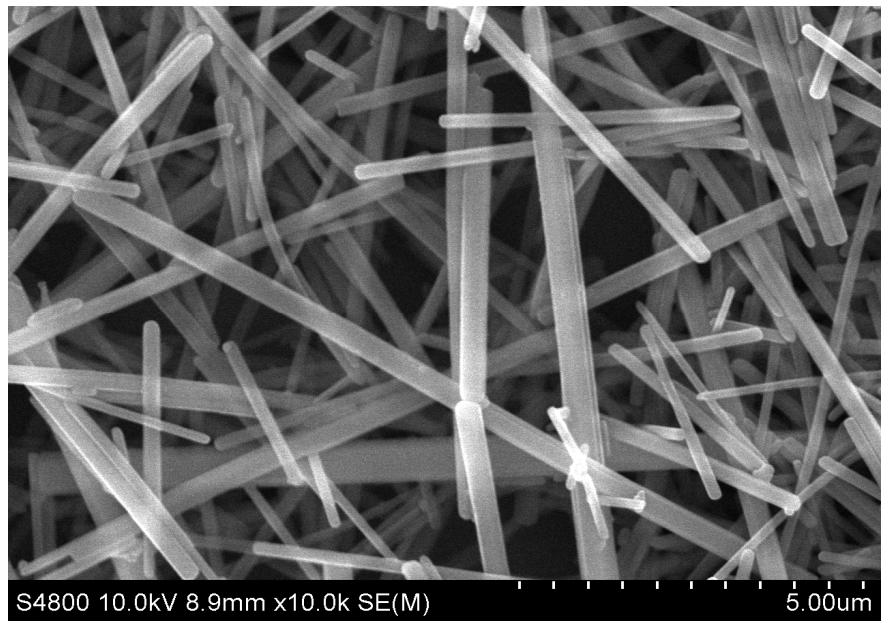

(c)

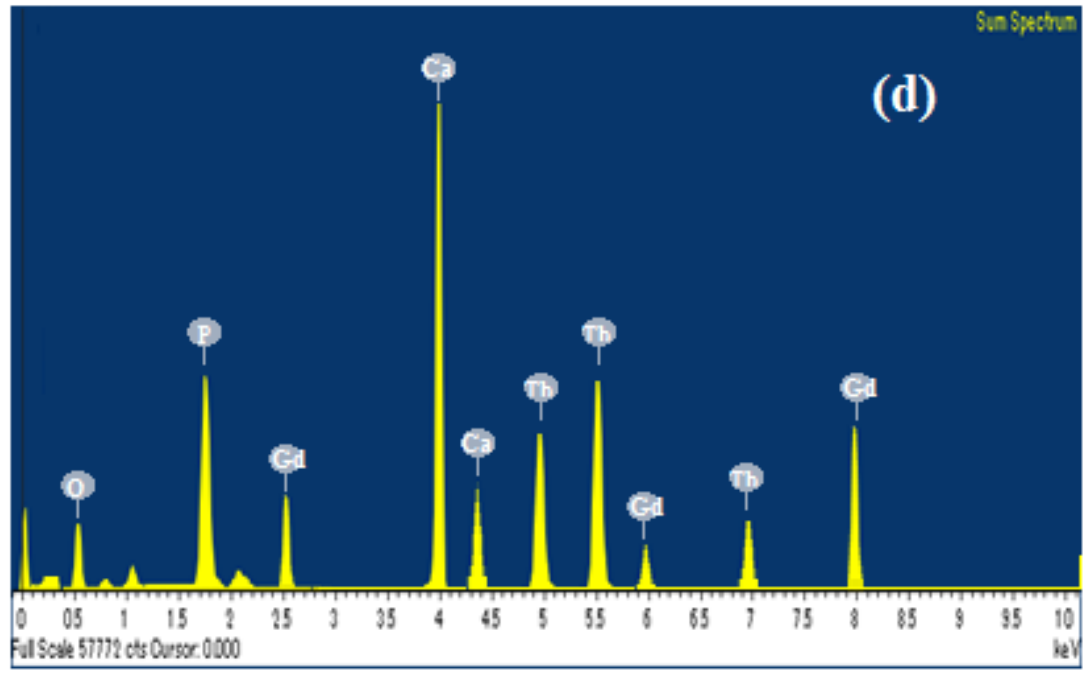

Figure 3. SEM micrographs of (a) Tb,Gd-HAP -1200 mV, (b) Tb,Gd-HAP -1400 mV, (c) Tb,Gd-HAP $-1600 \mathrm{mV}$ coatings on 316L SS. (d) EDAX spectrum of the Tb,Gd-HAP coating on $316 \mathrm{~L} \mathrm{SS}$

\section{Electrochemical studies}

The potentiodynamic polarization curves of uncoated, HAP coated and Tb,Gd-HAP coated on 316L SS in Ringer solution are shown in Figure 4. As indicated from the Figure (4a) corrosion potential $\left(\mathrm{E}_{\text {corr }}\right)$, breakdown potential $\left(\mathrm{E}_{\mathrm{b}}\right)$ and repassivation potential $\left(\mathrm{E}_{\mathrm{pp}}\right)$ for the uncoated $316 \mathrm{~L}$ SS were found to be at $-865,+447$ and $-88 \mathrm{mV} v s$. SCE, respectively. However, HAP coated samples the $\mathrm{E}_{\text {corr }}, \mathrm{E}_{\mathrm{b}}$ and $\mathrm{E}_{\mathrm{pp}}$ values were found to be $-790,+502$ and $185 \mathrm{mV}$ s. SCE, respectively. While the polarization parameter of $\mathrm{Tb}$, Gd-HAP coated on 316L SS shows values of $\mathrm{E}_{\text {corr }}=-662, \mathrm{E}_{\mathrm{b}}=+617$ and $\mathrm{E}_{\mathrm{pp}}=213 \mathrm{mV}$ vs. $\mathrm{SCE}$, respectively. When compared with the uncoated and HAP coated $316 \mathrm{~L} S \mathrm{SS}$, the $\mathrm{E}_{\mathrm{corr}}, \mathrm{E}_{\mathrm{b}}$ and $\mathrm{E}_{\mathrm{pp}}$ values of the Tb, Gd-HAP coated samples showed maximum shift towards the nobler direction. 
The Impedance spectroscopic studies of uncoated, HAP coated, Tb, Gd-HAP coated on $316 \mathrm{~L}$ SS samples are shown in Figure $4 \mathrm{~b}$. The polarization resistance $\left(\mathrm{R}_{\mathrm{p}}\right)$ of the Tb,Gd-HAP coating on 316L SS, which better polarization resistance $\left(R_{p}\right)$ of $1669 \Omega \mathrm{cm}^{2}$, which is higher than that obtained for the HAP coated on 316L SS $\left(796 \Omega \mathrm{cm}^{2}\right)$ and uncoated 316L SS $\left(45 \Omega \mathrm{cm}^{2}\right)$. The $\mathrm{E}_{\mathrm{corr}}, \mathrm{E}_{\mathrm{b}}, \mathrm{E}_{\mathrm{pp}}$ and $\mathrm{R}_{\mathrm{p}}$ values towards the noble direction is an indicated that the $\mathrm{Tb}, \mathrm{Gd}-\mathrm{HAP}$ coating possessed superior anti corrosion performance in Ringers solution.
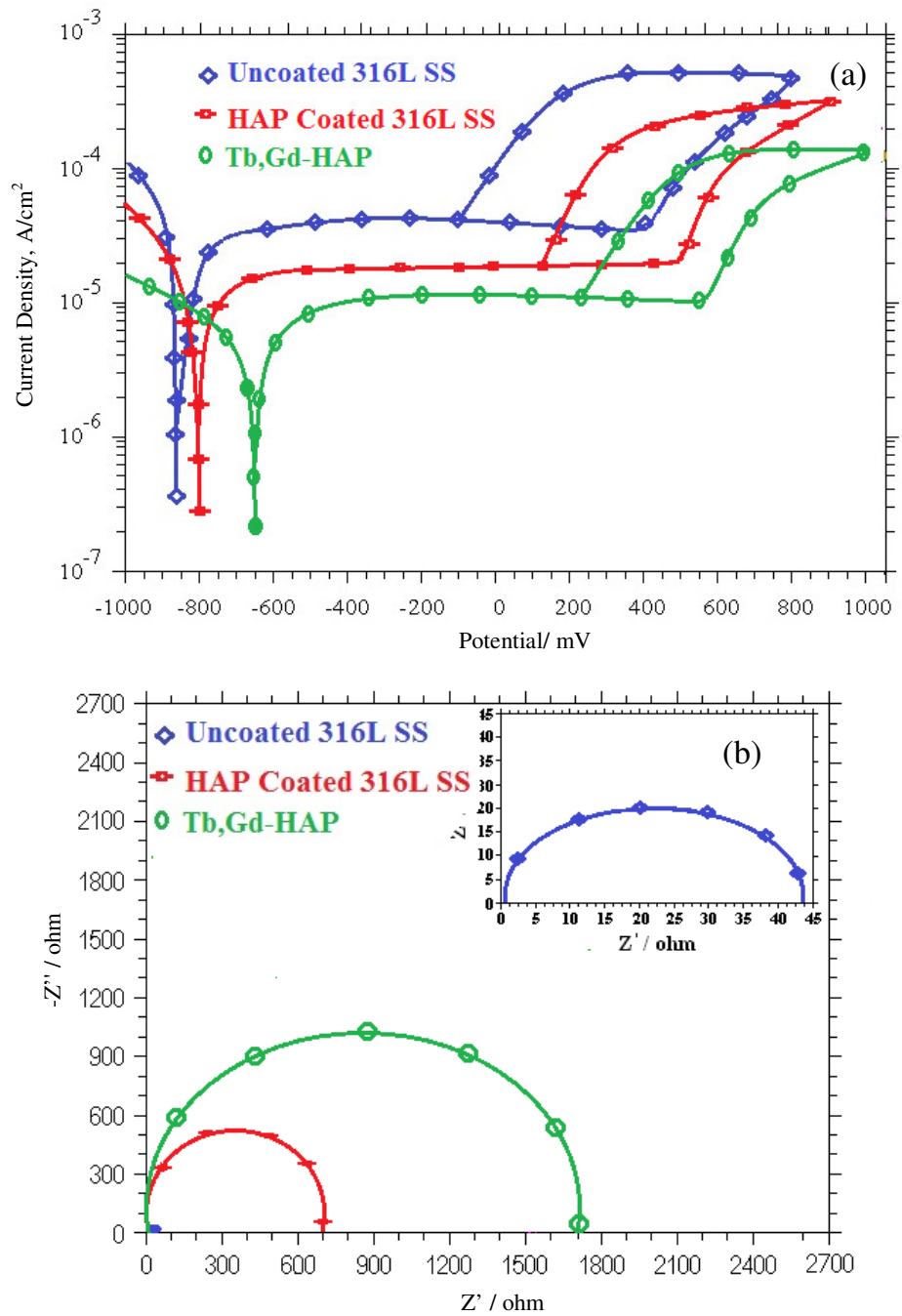

Figure 4. Electrochemical parameters of Tb, Gd-HAP coating on 316L SS

(a) potentiodynamic polarization curve and (b) Bode impedance plot

\section{Antibacterial Activity}

The antibacterial efficacy of the Tb, Gd-HAP coating at different concentrations was tested at against the pathogenic bacteria $S$. aureus (Gram-positive bacteria) and E. coli (Gram negative bacteria) by the disc diffusion method. The zone of inhibition around the Tb,Gd-HAP samples at various concentrations $(25,50,75,100$ and $125 \mathrm{~mL})$ against $E$. coli and $S$. aureus is 
indicated in Figure 5. The two prokaryotic strains of zone inhibition over the Tb, Gd-HAP coating was higher upon the increase of sample concentrations, when compared with control. In specifically, the action of the Tb, Gd-HAP coating against the negative bacteria (E. coli) strain was slightly higher when compared to that of Gram-positive bacteria (S. aureus). In this figure, the asterisk symbol $(*)$ denotes a significant difference compared to control $(\mathrm{P}<0.05)$.

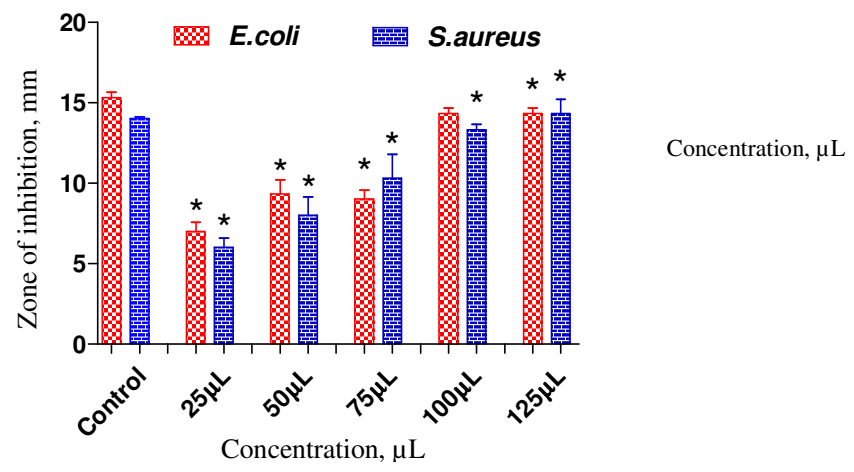

Figure 5. Antimicrobial activities of Tb,Gd-HAP coatings at different concentrations against pathogenic bacteria $S$. aureus and $E$. coli. The asterisk $(*)$ denotes a significant difference compared to control $(\mathrm{P}<0.05)$

\section{Live/Dead assay}

The cell proliferation of MC3T3-E1 cells on the Tb, Gd-HAP coated samples was determined using a MTT assay for 1, 3, 5 and 7 days of culture and the results are indicated in Figure 6. The evaluation of live/dead cells was carry out by culturing in medium for 1, 3, 5 and 7 days. The fluorescent microscopic images demonstrating the green are live cells, calcein acetomethylester (AM) was used for green. The number of live cells is increased and spreading elongated morphology as the incubation time increases. Although comparing the various days $(1,3,5$ and 7$)$ the $\mathrm{Tb}$, Gd-HAP coating exhibited superior cell proliferation and elongated morphology on 7 day, compared with other days $(1,3,5)$ of culture and control (Figure 7).

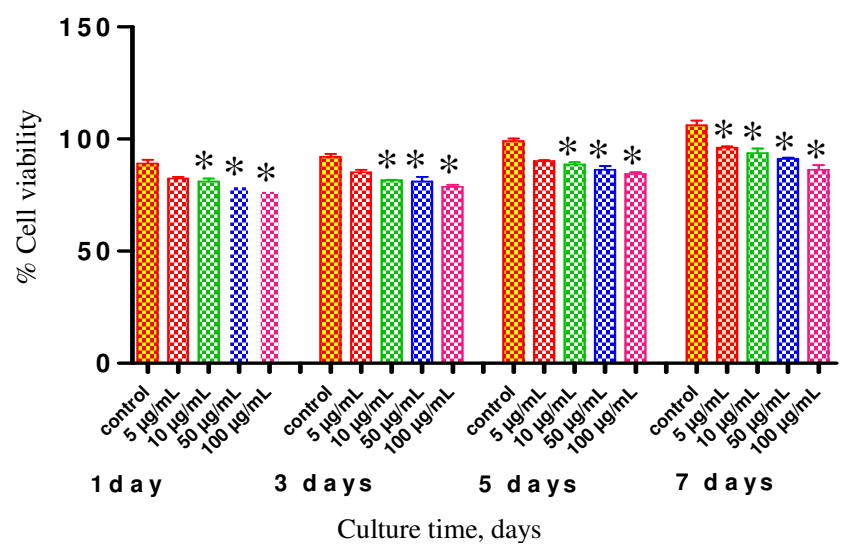

Figure 6. Cytotoxicity analysis of Tb,Gd-HAP coatings on MC3T3-E1 cells for 1, 3, 5 and 7 days. The asterisk symbol $(*)$ denotes a significant difference, compared to control $(\mathrm{P}<0.05)$ 


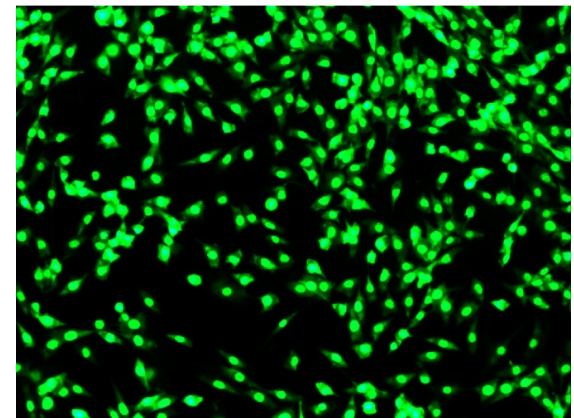

(a)

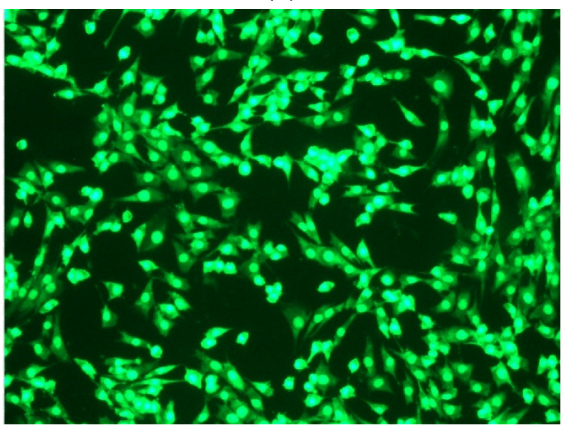

I

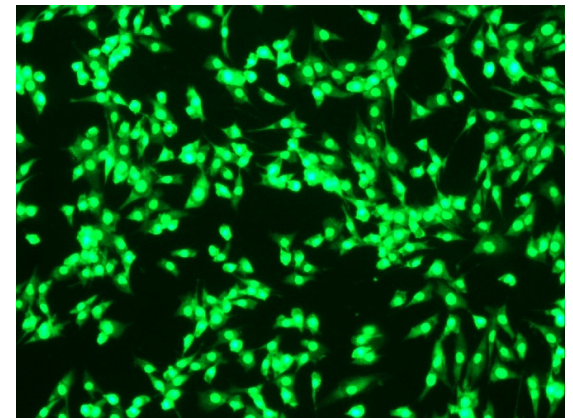

(b)

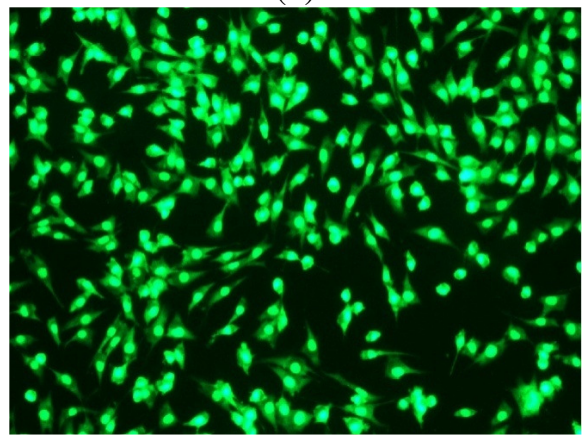

(d)

Figure 7. Live/dead cells fluorescence micrographs of osteoblasts cultured on Tb, Gd-HAP coating for (a) control, (b) 1 day, (c) days and (d) 7 days.

\section{Conclusion}

The development of Tb, Gd-HAP coating on 316L SS was successfully achieved by electrochemical deposition method. The FT-IR and XRD investigations confirmed the functional groups and phase purity of the Tb, Gd-HAP coating on 316L SS. The surface morphological results indicated that the Tb, Gd-HAP coating achieved on 316L SS with uniform surface fully covered rods. Hence, the electrochemical evaluations showed that the $\mathrm{Tb}, \mathrm{Gd}-\mathrm{HAP}$ coating exhibited superior anticorrosion properties in Ringers solution. The as formed $\mathrm{Tb}$, Gd-HAP coating possessed a better antibacterial property. The in vitro biocompatibility analysis indicate that the $\mathrm{Tb}, \mathrm{Gd}-\mathrm{HAP}$ coating promotes the cell viability and proliferation of the MC3T3-E1 cells. Thus, the Tb, Gd-HAP coating on 316L SS can be an choice implant material with enhanced properties for biomedical applications.

\section{References}

1. Hornberger H, Virtanen S and Boccaccini A R, Acta Biomater., 2012, 8(7), 24422455; DOI:10.1016/j.actbio.2012.04.012

2. Bavya Devi K, Singh K and Rajendran N, J Sol-Gel Sci Technol., 2011, 59(3), 513; DOI:10.1007/s10971-011-2520-x

3. Proskurovsky D I, Rotshtein V P, Ozur G E, Markov A B, Nazarov D S, Shulov V A, Yu F, Ivanov $\mathrm{R}$ and Buchheit G, J Vac Sci Technol A, 1998, 16, 2480; DOI:10.1116/1.581369

4. Huo H, Ying L and Wang F, J Mater Sci Technol., 2007, 23(3), 379-382. 
5. Afzal M A F, Kalmodia S, Kesarwani P, Basu B and Balani K, J Biomater Appl., 2013, 27(8), 967-978.

6. Tang Y, Katsuma S, Fujimoto S and Hiromoto S, Acta Biomater., 2006, 2(6), 709715; DOI:10.1016/j.actbio.2006.06.003

7. Kluba A, Bociaga D and Dudek M, Diamond Relat Mater., 2010, 19(5-6), 533-536; DOI:10.1016/j.diamond.2009.12.020

8. Sridhar T M, Kamachi Mudali U, Subbaiyan M, Corros Sci., 2003, 45(10), 23372359; DOI:10.1016/S0010-938X(03)00063-5

9. Javidi M, Javadpour S, Bahrololoom M E and Ma J Mater Sci Engg C, 2008, 28(8), 1509-1515; DOI:10.1016/j.msec.2008.04.003

10. Sivakumar M and Rajeswari S, J Mater Sci Lett., 1992, 11(15), 1039-1042; DOI:10.1007/BF00729754

11. Ballarre J, Lopez D A, Schreiner W H, Duran A and Cere S M, Appl Surf Sci., 2007, 253(17), 7260-7264; DOI:10.1016/j.apsusc.2007.03.007

12. Wen C, Guan S, Peng L, Ren C, Wang X and Hu Z, Appl Surface Sci., 2009, 255(13-14), 6433-6438; DOI:10.1016/j.apsusc.2008.09.078

13. Matsunaga K, Murata H, Mizoguchi T and Nakahira A, Acta Biomaterialia, 2010, 6(6), 2289-2293; DOI:10.1016/j.actbio.2009.11.029

14. Zheng $X$, Huang $M$ and Ding $C$, Biomaterials, 2000, 21(8), 841-849; DOI:10.1016/S0142-9612(99)00255-0

15. Geng F, Tan L L, Jin X X, Yang J Y and Yang K, J Mater Sci Mater Med., 2009, 20, 1149-1157; DOI:10.1007/s10856-008-3669-X

16. Yang $\mathrm{Y}$, Kim K H and Ong J L, Biomaterials, 2005, 26(3), 327-337; DOI:10.1016/j.biomaterials.2004.02.029

17. Serre C M, Papillard M, Chavassieux P, Voegel J C and Boivin G, J Biomed Maters Res., 1998, 42(4), 626-633; DOI:10.1002/(SICI)1097-

4636(19981215)42:4<626::AID-JBM20>3.0.CO;2-S

18. Morais D S, Coelho J, Ferraz M P, Gomes P S, Fernandes M H, Hussain N S, Santos J D and Lopes M A, J Mater Chem B, 2014, 2, 5872-588; DOI:10.1039/C4TB00484A

19. Ciobanu C S, Popa C L and Predoi D, J Nanomater., 2014, 780686;

DOI:10.1155/2014/780686

20. Yang C, Yang P, Wang W, Gai S, Wang J, Zhang M and Lin J, J Coll Int Sci., 2008, 328(1), 203-210; DOI:10.1016/j.jcis.2008.09.010

21. Yingguang L, Zhuoru Y and Jiang C, J Rare Earths, 2007, 25(4), 452-456; DOI:10.1016/S1002-0721(07)60455-4

22. Shang H B, Chen F, Wu J, Qi C, Lu B Q, Chen X and Zhu Y J, RSC Adv., 2014, 4, 53122-53129. DOI:10.1039/C4RA09902H

23. Escudero A, Calvo M E, Fernández S R, de la Fuente J M and Ocanna M, Langmuir, 2013, 29(6), 1985-1994; DOI:10.1021/la304534f

24. Chen F, Huang P, Zhu Y J, Wu J, Zhang C L and Cu D X, Biomaterials, 2011, 32, 9031-9039; DOI:10.1016/j.biomaterials.2011.08.032

25. Li L, Liu Y, Tao J, Zhang M, Pan H, Xu X and Tang R, J Phys Chem C, 2008, 112(32), 12219-12224; DOI:10.1021/jp8026463

26. El'kin O V and Kovalevskii A V, Russ J Electrochem., 2011, 47(7), 865-868; DOI:10.1134/S1023193511070068

27. Majeed S and Shivashankar S A, J Mater Chem B, 2014, 2, 5585-5593; DOI:10.1039/C4TB00763H 